\title{
A fundamentação moral dos direitos humanos
}

\author{
Giovani Mendonça Lunardi \\ Universidade Federal de Santa Catarina (UFSC), Campus \\ Araranguá
}

\section{A fundamentação moral dos direitos humanos}

Resumo: O objetivo deste trabalho é examinar a gramática moral kantiana e sua relação com a noção contemporânea de direitos humanos. Parte da hipótese de que a reflexão ética contemporânea sobre os fundamentos filosóficos dos direitos humanos está ainda na "clausura da moral" instaurada pelo "paradigma kantiano da razão prática". Na sequência, sustenta que a perspectiva de avaliação moral dos princípios norteadores dos direitos humanos segue, em grande medida, os determinados pelo pensamento crítico kantiano. Conclui formulando perspectivas de investigação e admitindo a importância de sua continuidade para a fundamentação filosófica dos direitos humanos.

Palavras-chave: Moral. Immanuel Kant. Direitos humanos.

\section{The Moral Foundation of Human Rights}

Abstract: The purpose of this work is to examine Kantian moral grammar and its relationship with the contemporary notion of human rights. It is based on the hypothesis that contemporary ethical reflections on the philosophical foundations of human rights are still within the "moral enclosure" established by the "Kantian paradigm of practical reason." It then affirms that the perspective of moral evaluation of the principal guidelines of human rights follows, to a large degree, the determinations of Kantian critical thinking. It concludes by formulating research perspectives and admitting the importance of their continuity for the philosophical foundation of human rights.

Key words: Moral. Immanuel Kant. Human rights. 


\section{Introdução}

Reivindicações para que os Estados nacionais também "ajam" de forma ética, rompendo com a tradição maquiavélica da separação entre moral e política, tornaram-se prementes, basicamente, a partir dos acontecimentos registrados nas guerras mundiais, nas guerras coloniais e na guerra fria do século 20 . Nesse contexto, marcado por inúmeras violações de direitos, tornou-se necessário construir toda uma normatividade internacional, a fim de resguardar e proteger esses direitos, até então inexistentes. Os Estados foram obrigados a fazer com que o respeito aos direitos humanos encontrasse efetiva proteção. $\mathrm{O}$ tema tornou-se preocupação comum dos Estados e um dos principais objetivos da comunidade internacional. Diante da "negação do valor da pessoa humana como valor fonte do direito", passou a emergir "a necessidade de reconstrução dos direitos humanos, como referencial e paradigma ético que aproxime o Direito da Moral" (PIOVESAN, 1997, p. 129). Por sua vez, guerras, genocídios e demais acontecimentos do século 20 tornaram emergencial uma reflexão teórica, a partir de uma filosofia política, com fundamentos normativos ressituados, submetidos aos acúmulos críticos de nossa civilização com novos parâmetros e paradigmas. Essa perspectiva permitiria ou mesmo produziria rupturas; mas sob uma mesma égide: "a elaboração de princípios fundamentais garantidores de um mínimo ético a ser respeitado pelo direito positivo" (MAIA, 2000, p. 5). Os filósofos políticos do século 20 que utilizamos nesta investigação Habermas, Alexy, Nino, Tugendhat, Bobbio - realizam essa reflexão tendo como "fio de Ariadne" o sistema filosófico de Immanuel Kant. Tal escolha teórica não é por mero acaso ou por conta de preferências acadêmicas. O filósofo alemão delimitou de certa forma os contornos teóricos de uma época, de um período, denominado hodiernamente de "modernidade" (HABERMAS, 2000). Seu discurso está incluído, juntamente com o de outros pensadores, no projeto Iluminista de fundamentação da moral e do direito, ambos submetidos ao "tribunal da razão". Com essas considerações iniciais, aventamos nossa primeira hipótese de trabalho, na qual sustentamos que os direitos humanos são direitos de "natureza moral".

\section{Direitos morais e direitos humanos}

A intuição de uma relação entre princípios morais e direitos humanos, segundo Habermas (1997, p. 140141), "não é de todo falsa, pois uma ordem jurídica só pode ser legítima, quando não contrariar princípios morais". O direito moderno, de acordo com o autor,

[...] deixa os seus endereçados livres para, ou observarem as normas apenas como uma restrição fática [faktisch] do seu âmbito de ação - e se ajustarem a um relacionamento estratégico com as consequências calculáveis das possíveis violações das regras -, ou quererem obedecer as prescrições 'por respeito diante da lei'. [...] Normas jurídicas devem ser feitas de tal modo que possam ser vistas ao mesmo tempo sob aspectos diferentes como leis coativas e como leis da liberdade. Deve ser no mínimo possível seguir normas jurídicas não porque elas coagem, mas sim porque são legítimas. A validade [Gültigkeit] de uma norma jurídica afirma que o poder estatal garante ao mesmo tempo positivação jurídica legítima e execução judicial fática (HABERMAS, 2001 apud SILVA, 2008, p. 4).

Para o filósofo alemão (2001, p. 144), o direito "reclama não apenas aceitação; ele demanda dos seus endereçados não apenas um reconhecimento fático, mas antes reivindica 'merecer' o reconhecimento". Habermas ratifica que, através dos componentes de legitimidade da validade jurídica, o direito adquire uma relação com a moral. A tensão entre a positividade do direito e sua pretensão de legitimidade está latente no próprio direito. O autor (1997, p. 141) reconhece que:

[...] as questões morais e jurídicas referem-se aos mesmos problemas: como é possível ordenar legitimamente relações interpessoais e coordenar entre si ações servindo-se de normas justificadas? Como é possível solucionar consensualmente conflitos de ação com base em regras e princípios normativos reconhecidos intersubjetivamente?

Os direitos constitucionais positivados que se revestem de legalidade e, ao mesmo tempo, permitem o cumprimento de exigências de legitimidade e justificação são aqueles que garantem os denominados direitos fundamentais ou direitos humanos. Para Habermas (1997, p. 128), "a ideia dos direitos humanos e a da soberania do povo determinam até hoje a autocompreensão normativa de Estados de direito democráticos". Ou seja, os direitos humanos, nas sociedades contemporâneas, tornam-se cada vez mais o "medium" do direito positivo que se pretende legítimo, conectado com a moral.

Acolhemos também a sugestão de Alexy (1999, p. 60): "direitos humanos são direitos morais". Como sustenta da mesma forma Carlos Nino (1989, p. 19): "os direitos humanos são direitos estabelecidos por princípios morais". O jusfilósofo argentino é ainda mais radical, para ele, a fundamentação da natureza moral dos direitos humanos independeria de qualquer ordem jurídica nacional ou tratado internacional protetivo.

Os direitos fundamentais constitucionais são, em última instância, direitos morais; que compartilham características comuns aos princípios morais, tais 
como: autonomia, liberdade, igualdade, universalidade, respeito, dignidade, reconhecimento, entre outros. Escreve Alexy (1999, p. 60):

[...] direitos morais podem, simultaneamente, ser direitos jurídico-positivos; sua validez, porém, não pressupõe uma positivação. Para a validez ou existência de um direito moral basta que a norma, que está na sua base, valha moralmente. Uma norma vale moralmente quando ela, perante cada um que aceita uma fundamentação racional, pode ser justificada.

O discurso jurídico dos direitos humanos mostra sua verdadeira face como direitos morais, principalmente nas controvérsias constitucionais, quando reivindica um discurso justificatório mais amplo, aberto às razões de ordem pragmática e ética, conectado com princípios morais (SILVA, 2008). Esse espraiamento da argumentação dos direitos humanos como direitos fundamentais constitucionais e, ao mesmo tempo, como direitos morais "liquefaz" a tese da dicotomia direito e moral, tão cara à tradição positivista para identificação do fenômeno jurídico ${ }^{1}$.

Da mesma forma, Ernst Tugendhat (2003) explicita nossa hipótese: a "fundamentação" filosófica dos direitos humanos é uma "fundamentação" moral. Para ele, os direitos humanos levam a um conceito central da moral política, assegurando o que ele denomina de "justificação moral do estado" em contraposição à "justificação contratualista clássica" (TUGENDHAT, 2003 apud NAHRA, 2007, p. 153). A “fundamentação" moral do Estado, segundo Tugendhat, precisa prever tanto os direitos individuais quanto coletivos. O poder do Estado moderno só é "legítimo" se se baseia de certa maneira nos interesses de todos, e a existência dos direitos humanos teria de significar que eles são incluídos nesse interesse de todos (TUGENDHAT, 2003 apud NAHRA, 2007, p. 153-155). Percebemos que a própria terminologia utilizada na discussão filosófica dos direitos humanos - "fundamentação", "legitimação", "justificação"-é uma "gramática moral"2 que remete diretamente às reflexões da ética ${ }^{3}$.

Até o presente momento, estabelecemos nossa primeira hipótese: a reflexão filosófica sobre a fundamentação dos direitos humanos está ancorada inexoravelmente em uma discussão a respeito da justificação ou legitimação desses direitos sujeitos à avaliação moral. De certa forma, o debate filosófico a respeito dos direitos humanos residirá de alguma forma no âmbito da ética.
A segunda hipótese sustenta que a reflexão ética determinante para a fundamentação moral dos direitos humanos está predominantemente submetida ao "paradigma kantiano da razão prática". Nossa suspeita é que o discurso filosófico atual de fundamentação dos direitos humanos está ainda "dependente" da fundamentação moral kantiana com seu "ideal de racionalidade prática".

\section{0 paradigma kantiano da razão prática: da moral ao direito}

Desde Sócrates, Platão e Aristóteles a busca pela fundamentação e justificação de princípios primeiros e últimos é uma tradição que nasce com a própria filosofia e, por conseguinte, com implicações para as suas demais áreas de interesse. Dentro da ética filosófica, essa tradição tem sua formulação precisa na Fundamentação da metafísica dos costumes de Immanuel Kant (1980). Ou seja, a reflexão filosófica sobre a fundamentação, legitimação ou justificação de normas e regras de conduta vinculadas a princípios morais, não é novidade.

De acordo com Höffe (2005, p. 232), o filósofo de Königsberg já havia estabelecido para a "ideia moderna dos Direitos Humanos o mais elevado padrão de medida". Segundo Kant (HECK, 2007, p. 106), "a própria humanidade é uma dignidade". Neste momento, explicitamos o segundo aspecto de nossa investigação: a reflexão ética contemporânea sobre os fundamentos filosóficos dos direitos humanos está ainda na "clausura da moral" 4 instaurada pelo "paradigma kantiano da razão prática". O que sustentamos é que a perspectiva de avaliação moral dos princípios norteadores dos direitos humanos segue, em grande medida, os determinados pelo pensamento crítico kantiano. Ou seja, a "ideia de razão prática kantiana" é fundamental para as tentativas contemporâneas de legitimação dos direitos humanos.

Esse paradigma está baseado na confiança na razão; e, no âmbito da moral, em termos kantianos, na razão prática ${ }^{5}$. Segundo Heck (2007, p. 144), "a razão prática é o coração da doutrina moral de Kant”. O filósofo alemão apresenta, com sua "crítica" da razão, uma concepção substancial de racionalidade prática que contrasta com a proposta inicial de Aristóteles. Desde Hegel, reafirma-se sempre de novo que, à diferença de Aristóteles, falta-lhe um conceito de práxis; que a razão prática é de fato uma razão teórica que se coloca a serviço de objeti- 
vos práticos. Mas essa é justamente a originalidade do pensamento kantiano: a razão teórica é "efetivamente prática", ou, na terminologia kantiana, uma "razão pura prática".

Deveríamos, neste momento de nossa investigação, explicitar a "teoria crítica de Kant" e seu movimento de passagem da "razão pura" para "razão prática” (KANT, 1988, 2003a). Por limitações de espaço, indicamos referências de comentadores que realizam tal tarefa: Höffe (2005) e Wood (2008). Cumpre alertar que qualquer tentativa exegética do pensamento kantiano será sempre insuficiente ou incompleta. Isso decorre basicamente do alcance a que se lançou o projeto filosófico kantiano. O filósofo alemão elaborou através das "críticas da razão", segundo suas próprias palavras, uma "revolução copernicana na filosofia” (KANT, 1997, p. 153).

Mas, o que nos interessa neste trabalho é que a razão kantiana está contida na decisão da razão a favor de si mesma, isto é, está embutida em uma decisão que a estabelece como fundamento. A legislação da razão não tem, para Kant, como expressar outra coisa senão ela própria e também não procura outra coisa senão a si mesma. Escreve o filósofo alemão (2003, p. 71):

[...] mas para a sua legislação [a razão] requer-se que ela necessite pressupor-se simplesmente a si mesma, porque a regra só é objetiva e universalmente válida se vale independente de condições subjetivas e contingentes, que distinguem um ente racional de outro.

Apesar de seus críticos, a concepção kantiana de racionalidade prática mantém-se atual. Isso porque, basicamente, na recente discussão sobre a justificação de juízos morais, Kant opõe-se, do mesmo modo que os representantes da ética utilitarista e do princípio de universalização (Hare, Singer), ao relativismo, ceticismo e dogmatismo na ética. Mas também porque Kant considera que o julgar e o agir moral não são uma questão de um sentimento pessoal ou de uma descrição arbitrária, tampouco uma questão de origem sociocultural, de tato ou de estudada convenção. Segundo o filósofo alemão, a razão prática não é simples instrumento para administrar interesses. O homem tem necessidades sensíveis e vitais, mas isso não significa que a única função da razão prática seja a conservação do organismo ou que ela seja um órgão promotor da felicidade humana. Se assim o fosse, a atividade seria, antes, apenas inteligente ou prudencial e não constituiria nenhuma diferença entre o animal e o homem.

A ideia kantiana de uma razão prática é justamente a de uma vontade que realiza a passagem entre o reconhecimento do "princípio" e a "ação" a ele conforme a representação da lei moral. Afirma Kant (1980, p. 111):
[...] a razão nos foi dada como faculdade prática, isto é, como faculdade que deve exercer influência sobre a 'vontade', então o seu verdadeiro destino deverá ser produzir uma 'vontade', não só ‘boa' quiçá como 'meio' para outra intenção, mas uma 'vontade boa em si mesma', para o que a razão é absolutamente necessária, uma vez que a natureza de resto agiu em tudo com acerto na repartição das suas faculdades e talentos.

Por isso, para Kant (1980, p. 123), “a vontade não é outra coisa senão a razão prática”. Essa asserção da "fundamentação" de que a vontade não é outra coisa senão razão prática constitui a marca de seres cuja conduta está em conformidade com as regras da razão que determinam naturalmente o que é bom. A razão prática é vontade, e somente seres racionais têm vontade.

O homem, todo ser humano, tem um "valor absoluto" porque é capaz de "boa vontade", isto é, porque tem consciência de poder colocar seu agir sob o ditame da razão prática. É porque o ser humano é sujeito da razão prática que ele é autônomo, que ele se dá sua própria lei. É porque o ser humano é sujeito da razão que ele tem dignidade e não um preço, porque seu valor é absoluto e não relativo como tudo o que tem um preço. Assim, a moral de Kant é uma moral da razão prática, porque é só pela razão que o homem consegue de fato tornar-se autônomo. O ser humano é essencialmente autônomo, não por pertencer a uma determinada comunidade, não por compartilhar com os outros uma determinada tradição, mas por ser sujeito da razão incondicional.

O alcance da razão prática, segundo Kant, determina dois aspectos fundamentais da moralidade: primeiro, é unicamente a razão que torna o homem incondicionalmente autolegislador; segundo, se a razão é incondicionalmente legisladora, então, nenhuma concepção da prudência ou do egoísmo generalizado poderá suplantar o lugar insubstituível da razão. Se a razão é incondicionalmente legisladora, então, nenhuma regra de decisão da razão instrumental, estratégica ou prudencial, nenhuma racionalidade "meios-fins", nenhuma eticidade convencional do mundo da vida poderá pretender substituir os papéis absolutamente inalienáveis da razão, que tem sua sede no ser humano. Nós nos distinguimos de todos os outros seres por meio da capacidade de escolha racional de nossas ações. Portanto, de acordo com Kant, a condição de base para a ação moral é a "autonomia" - a capacidade que cada um de nós tem de impor restrições morais a nós mesmos. O homem racional, dotado de vontade livre e autolegisladora, confere a si mesmo a norma do agir moral.

Distintamente das teorias do egoísmo ético e do senso moral, Kant vai afirmar que o agente não atinge a autonomia moral se desejos, emoções e inclina- 
ções governarem seus julgamentos morais. Quando agimos de acordo com desejos, emoções e inclinações, estamos, simplesmente, respondendo às necessidades físicas, da mesma forma que os animais. Assim, quando nossas ações refletem somente nossos desejos e inclinações (imperativos hipotéticos), e não a nossa capacidade de raciocínio moral, elas não são livres e, consequentemente, não têm valor moral, uma vez que a moralidade exige a liberdade (KANT, 2003). Segundo o filósofo alemão (2003, p. 23),

[...] o conceito de liberdade é a pedra de escândalo para todos os empiristas, mas também a chave das mais sublimes proposições fundamentais práticas para moralistas críticos, que com isso tem a perspiciência de que precisam proceder de modo necessariamente racional.

Para Kant, os requisitos da moral derivam do fato de que os seres humanos são seres livres e podem exercitar essa liberdade pelo raciocínio moral. $\mathrm{O}$ suporte do conhecimento normativo é a autonomia da razão pura prática. Esse primado autônomo da razão pura prática ampara a convicção segundo a qual perguntas normativas podem receber respostas verdadeiras.

Ainda de acordo com o filósofo alemão, as apreciações morais, que distinguem entre o correto e o incorreto, o legítimo e o ilegítimo, o justo e o injusto, não constituem meras expressões dos sentimentos familiares de aprovação e reprovação, agrado e desagrado, aversão e simpatia, e assim por diante. Existe, segundo Kant, um princípio filosófico moral, objetivamente válido e universalmente vinculante, acessível ao conhecimento humano, que estabelece uma linha divisória inalterável entre o moralmente permissível e o moralmente condenável. Tal princípio oferece critérios à luz dos quais a qualidade moral (e também jurídica) das ações humanas pode ser julgada.

Essa visão de Kant consolida então, em nossa tradição, o que denominamos "paradigma kantiano da razão prática": princípios da razão prática são normativos, para nós, porque simplesmente somos racionais (DARWALL, 1983). Racional, em um sentido kantiano, significa que está presente uma força normativa segundo a qual o relevante na ação do agente não é como ele "quer" agir, mas como ele "deve" racionalmente agir. Ou seja, a normatividade dos juízos morais, de acordo com uma racionalidade prática, implica a ideia de considerações racionais (DARWALL, 1983).

Assim, segundo a visão kantiana, a justificação da moralidade é uma "dedução" de princípios dos princípios de racionalidade (DREIER, 1997, p. 83). As razões para um agente agir são considerações que guiam racionalmente a ação. Aqui há um ponto que merece ser destacado: segundo Kant, "a justifica- ção da moralidade é o mesmo que a justificação da racionalidade".

De acordo com Allen Wood (2008, p. 206),

[...] para Kant, o sistema de direito começa com um único direito inato que todo ser humano tem em virtude de sua humanidade ou natureza racional - o direito à liberdade ou a independência de não ser coagido pela vontade arbitrária de outro.

Podemos afirmar então que o conceito-chave do pensamento kantiano, que permite a passagem da moral para o direito, será o conceito de liberdade, ou seja, de razão autônoma, de vontade livre. Como afirma Valério Rohden (1997, p. 12):

A filosofia prática e mesmo toda a filosofia crítica de Kant funda-se sobre o conceito de liberdade, baseado nela o homem tem de decidir se transforma a si próprio e opta pela paz como fundamento, característica e norma da política, ou se abdica da certeza do seu futuro humano.

Kant utiliza a liberdade (vontade livre) que, como fundamento da moralidade, não se restringe ao indivíduo e à sua conduta subjetiva, mas é também liberdade partilhada (e compatibilizada) com os outros. Para Kant, o problema central da vida política está na administração legal da liberdade, já que todos os seres humanos são igualmente livres (LANDIM, 1996). Esse problema da comunidade política será resolvido pela proposta de uma ordem legal (jurídica), independente de qualquer experiência, que estabelece e garante a coexistência externa e pública das liberdades (KANT, 2003). Então, na vida política, a liberdade "deixa-se" delimitar pelo direito. Kant aborda a vida política pelo ângulo do direito, do qual faz um estudo sistemático na primeira parte da Metafísica dos costumes e em vários escritos, como a Ideia de história sobre o ponto de vista cosmopolita (1784) e Em direção à paz perpétua (1795). A vida política, segundo ele, não exige a obediência a princípios subjetivos, mas só o cumprimento público da lei que delimita o exercício externo da liberdade (LANDIM, 1996, p. 189).

Dois são os tipos de leis que delimitam o exercício da liberdade:

a) as leis jurídicas, que se referem às ações externas e à sua legalidade;

b) as leis éticas, ou leis da moralidade, que exigem que as próprias leis sejam o princípio de determinação das ações.

Ambas são morais por serem "leis da liberdade", diferenciando-se, assim, das leis da natureza (KANT, 2003, p. 82). A delimitação da liberdade é necessária para a vida política.

Kant vai conceituar o direito da seguinte forma: "O direito é, portanto, o conjunto das condições sob 
as quais o arbítrio de um pode unir-se ao arbítrio de outro segundo uma lei universal da liberdade."

E o "princípio universal do direito" é definido como:

Qualquer ação é justa se for capaz de coexistir com a liberdade de todos de acordo com uma lei universal, ou se na sua máxima a liberdade de escolha de cada um puder coexistir com a liberdade de todos de acordo com uma lei universal (KANT, 2003, p. 76-77).

Portanto, são as máximas da moralidade que orientam e definem as ações que a liberdade de arbítrio pode fazer (ou deve evitar) para que a liberdade do próximo não seja violada. Finalmente, sintetizando o conceito e o princípio, Kant (2003, p. 77) formula a "lei universal do direito" de modo imperativo: "age externamente de modo que o livre uso de teu arbítrio possa coexistir com a liberdade de todos de acordo com uma lei universal."

A razão desse imperativo é conhecida; o homem, um ser finito, não adere espontaneamente ao princípio do direito que, por si mesmo, deve ser imposto sob forma a priori, anterior a qualquer experiência histórica, para que as liberdades possam coexistir na sociedade política (LANDIM, 1996). Só é moralmente legítimo (justo) o direito (a lei) que garante a cada cidadão uma liberdade da ação compatível com a dos outros. Pode-se dizer que a "lei universal do direito" é o imperativo categórico da vida social. A liberdade é, segundo Kant, o supremo direito humano, fundador de todos os outros. Existe somente um direito inato, que precede toda a legislação positiva e que serve de critério de legitimidade: a liberdade compatibilizada com a liberdade dos outros. Kant (2003, p. 83) escreve:

A liberdade, na medida em que pode coexistir com a liberdade de qualquer outro segundo uma lei universal, é este direito único, originário, que corresponde a todo homem em virtude de sua humanidade.

Portanto, a liberdade não é ilimitada, mas compatibilizada. Escreve Kant (2003, p. 82) na Doutrina da virtude:

Mas um ser humano considerado como uma pessoa, isto é, como o sujeito de uma razão moralmente prática, é guindado acima de qualquer preço, pois como pessoa (homo noumenon) não é para ser valorado meramente como um meio para o fim dos outros ou mesmo para seus próprios fins, mas como um fim em si mesmo, isto é, ele possui uma 'dignidade' (um valor interno absoluto) através do qual cobra 'respeito' por si mesmo de todos os outros seres racionais do mundo. Pode avaliar a si mesmo conjuntamente a todos os ou- tros seres desta espécie e valorar-se em pé de igualdade com eles.

Em Kant (HABERMAS, 1997, p. 140), “a legislação moral 'reflete-se' na jurídica, a moralidade, na legalidade, os deveres éticos, nos deveres jurídicos etc."

Na Doutrina do direito ele explicitamente apresenta seu "direito de humanidade": "não faças de ti mesmo apenas um meio para os outros, mas sejas simultaneamente um fim para eles" (KANT, 2003, p. 82). Na interpretação de Heck (2007, p. 106):

A unicidade do direito subjetivo kantiano confere traços de inconfundibilidade ao direito de humanidade. Embutida na razão pura prática, a noção de um direito inato à liberdade humana unifica, sob o conceito de humanidade, quatro títulos diversos, ou seja, o direito à igualdade, o direito de ser senhor de si mesmo, o direito à inocência presumida e o direito de confrontar o outro com minha vontade, sem subverter o seu livre arbítrio. Para Kant, essas quatro determinações jurídicas estão analiticamente contidas no direito subjetivo próprio a cada homem, em razão de sua humanidade.

Kant fundamenta o direito, o Estado e a própria moral na razão prática pura ${ }^{6}$. O critério kantiano de direito implica um critério pelo qual todas as leis positivas são julgadas a respeito de sua legitimidade. São racionais ou inteiramente legítimas apenas aquelas prescrições jurídicas que garantem, conforme leis estritamente universais, a compatibilidade da liberdade de um com a liberdade de todos os outros (HÖFFE, 2005).

Assim, o conceito racional do direito de Kant possibilita também a ideia dos direitos humanos. Segundo Höffe (2005, p. 242), na visão kantiana,

[...] os direitos humanos são aqueles direitos que competem a todo ser humano como tal, independentemente de circunstâncias pessoais, de constelações políticas e de condições históricas. Como é juridicamente lícita toda ação que seja compatível com a liberdade de todos os outros, compete 'a todo homem, em virtude da sua humanidade', aquele grau de liberdade que 'possa coexistir com a liberdade de qualquer outro, conforme a uma lei universal'. A liberdade compatível com a liberdade de todos os demais é o único direito humano; poderse-ia dizer também: o único critério de todos os direitos humanos.

A atualidade dessa correlação entre moral e direito, e, por conseguinte, com direitos humanos estabelecida por Kant, pode ser comprovada nos seguintes "jusfilósofos" contemporâneos: Rawls, Tugendhat, Habermas, Nino e Alexy ${ }^{7}$. Todos susten- 
tam e realizam "reconstruções" sofisticadas e originais do pensamento kantiano; no entanto, cada um, a sua maneira e em diferentes graus, mantém a mesma fundamentação filosófica kantiana entre "direitos humanos" e "princípios morais".

No entanto, essa dependência da fundamentação filosófica dos direitos humanos dos pressupostos teóricos da moral kantiana não é consenso entre vários pensadores, estando sujeita a diversos questionamentos.

\section{Críticas ao idealismo kantiano dos direitos humanos}

Noberto Bobbio (2004, p. 43) afirma que o maior problema com relação aos direitos humanos não é filosófico, mas político, qual seja, protegê-los.

Na sua Autobiografia, publicada em 1997, três anos depois de sua morte, Bobbio revela um profundo pessimismo com relação ao seu século (o Novecento - " "sou filho de um século que será forçosamente recordado como o mais cruel da história" e ao futuro da humanidade - "como tenho dito tantas vezes, a história humana, entre a salvação e a perdição, é ambígua. Não sabemos nem mesmo se somos nós os donos de nosso destino." Ele escreve que "devemos reconhecer [...] que o nosso senso moral avança, mas, no entanto, avança mais lentamente que o avanço do poder econômico, do poder político, do poder tecnológico." Critica que todas as nossas proclamações de direitos estão apartadas de nossa realidade, ficam restritas "ao mundo do ideal, ao mundo daquilo que deveria ser" (BOBBIO, 1997, p. 261).

Sua visão é que os direitos do homem (diritti dell'uomo) são uma grande invenção da nossa civilização, mas uma invenção mais "anunciada que seguida” (BOBBIO, 1997, p. 257, 263). Esse novo ethos mundial dos direitos do homem resplandece em todas as declarações internacionais e nos congressos mundiais que os celebram e os comentam, no entanto, é sistematicamente violado em "quase" todos os países do mundo (diz Bobbio, 1997, p. 261-262: “podemos afirmar 'todos', sem medo de errar"), sejam ricos ou pobres, potentes ou fracos etc.

Da mesma forma, esse pessimismo do filósofo italiano recai também em críticas às tentativas de fundamentação filosófica dos direitos humanos. $\mathrm{O}$ alvo das suas críticas é a fundamentação moral dos direitos humanos de Kant. Para o filósofo alemão, segundo Bobbio (2000, p. 475-476), a Revolução Francesa representou "uma disposição moral da espécie humana", através de uma constituição "em harmonia com os direitos naturais dos homens, de tal feita que estes que obedecem à lei devam também, reunidos, legislar”. Bobbio (2000, p. 483) desconfia da certeza de Kant e do Iluminismo, pois, para ele, os direitos do homem como sinal de progresso moral da humanidade, como crescimento moral, deveria ser medido "não pelas palavras, mas pelos fatos".

Também Thomas Nagel (1999, p. 33) escreve que "a evidente violação dos direitos humanos mais fundamentais é privada de interesse filosófico". É claro que Nagel não está afirmando que a discussão sobre os fundamentos ou o status dos direitos fundamentais não seja de interesse filosófico. O que ele sustenta é que não é necessária nenhuma discussão filosófica particularmente elaborada e refinada para estabelecer quais são esses direitos fundamentais e quando eles estão sendo transgredidos. Com esse mesmo sentido afirma W. Kersting (2003, p. 92),

\section{[...] eu não preciso mergulhar numa cultura para tomar conhecimento do genocídio, da persegui- ção de minorias, da privação de grupos popu- lacionais inteiros de seus direitos como violações dos direitos humanos. Expulsões e valas comuns não têm uma gramática cultural que demandaria uma hermenêutica difícil. Elas próprias mostram o que significam.}

De forma geral, tais críticas estão endereçadas principalmente à pretensão iluminista - e por que não dizer kantiana - de um ideal de razão prática com uma fundamentação absoluta e universal dos direitos humanos.

\section{Considerações finais}

Percebemos a exigência ética dos direitos humanos, presentes nos acontecimentos recentes do século 21, expressa no fenômeno da "constitucionalização do Direito", localizado em todos os Estados da atualidade e em suas relações supranacionais que reivindicam exigências de legitimidade e justificação para além da legalidade de sua normatividade jurídica. Afirma Carlos Nino (1994, p. 62), que "a validez de certo ordenamento jurídico não pode fundar-se em regras desse mesmo sistema jurídico, mas deve derivar de princípios externos ao próprio sistema". Princípios estes, que, conforme sustentamos neste trabalho, são os princípios kantianos da razão prática.

Diante do exposto, podemos formular as seguintes perspectivas de investigação para continuidade desta pesquisa: verificar a plausibilidade dessas críticas; apresentar alternativas de teorias éticas ao paradigma kantiano; ou alternativas de possíveis fundamentos filosóficos para os direitos humanos. Porém, todas essas perspectivas de investigação somente poderão ser objeto de exame em outros momentos.

De qualquer forma, a continuidade da investigação pela busca da fundamentação dos direitos hu- 
manos faz-se necessária para, pelo menos, não termos de admitir, de imediato, que Kant estivesse certo a maior parte do tempo.

\section{Referências}

ALEXY, R. Direitos fundamentais no Estado constitucional democrático: para a relação entre direitos do homem. Revista de Direito Administrativo, Rio de Janeiro, v. 217, p. 55-66, jul./set. 1999.

BARBOSA, A. P. C. A legitimação dos princípios constitucionais fundamentais. Rio de Janeiro: Renovar, 2002.

BOBBIO, N. Autobiografia. A cura di Alberto Papuzzi. Roma: Editori Laterza, 1997. (Tradução nossa, obra ainda não publicada no Brasil). pus, 2000.

Teoria geral da política. Rio de Janeiro: Cam-

A era dos direitos. Tradução de Carlos Nélson Coutinho. Rio de Janeiro: Elsevier, 2004.

DARWALL, S. Impartial Reason. Ithaca: Cornell University Press, 1983.

DREIER, J. Humean Doubts about the Practical Justification of Morality. In: CULLITY, G.; GAUT, B. (Ed.). Ethics and Practical Reason. Oxford: Clarendon Press, 1997, p. 81-99.

DUTRA, D. J. V. O acesso comunicativo ao ponto de vista moral. Síntese Nova Fase, Belo Horizonte, v. 25, n. 83, p. 509-526, 1998.

FELDHAUS, C. Direito e moral: três estudos a respeito da filosofia prática de Kant. Florianópolis: Apolodoro Editora, 2007.

FERNANDEZ, E. Teoría de la justicia y derechos humanos. Madrid: Editorial Debate, 1991.

FERRAJOLI, L. et al. Los fundamentos de los derechos fundamentales. Madrid: Editorial Trotta, 2001.

HABERMAS, J. Direito e democracia: entre faticidade e validade. Rio de Janeiro: Tempo Brasileiro, 1997. (v. 1).

O discurso filosófico da modernidade. São Paulo: Martins Fontes, 2000.

Acerca da legitimação com base nos direitos humanos. In: A constelação pós-nacional.
Tradução de Marcio S. Silva. São Paulo: Littera Mundi, 2001, p. 147-149.

HECK, J. N. Da razão prática ao Kant tardio. Porto Alegre: Editora da PUC-RS, 2007.

HÖFFE, O. Immanuel Kant. Tradução de Christian Viktor Hamm e Valério Rodhen. São Paulo: Martins Fontes, 2005.

HONNETH, A. Lutas por reconhecimento: a gramática moral dos conflitos sociais. Tradução de Luiz Repa. São Paulo: Editora 34, 2003.

KANT, I. Fundamentação da metafísica dos costumes. Tradução de Paulo Quintela. São Paulo: Abril, 1980. (Coleção Os Pensadores).

Prolegômenos a toda metafísica futura. Lisboa: Edições 70, 1988.

Crítica da razão pura. Tradução de Manuela Pinto dos Santos e Alexandre Fradique Morujão. Lisboa: Fundação Calouste Gulbenkian, 1997.

. A metafísica dos costumes. Tradução de Edson Bini. Bauru: Edipro, 2003.

. Crítica da razão prática. Tradução, introdução e notas de Valério Rodhen. São Paulo: Martins Fontes, 2003a. (Edição bilíngue).

KELSEN, H. Teoria pura do direito. São Paulo: Martins Fontes, 1991.

KERSTING, W. Em defesa de um universalismo sóbrio. In: ______. Universalismo e direitos humanos. Porto Alegre: Editora da PUC-RS, 2003, p. 92-102.

LANDIM, M. L. P. F. A liberdade em Kant. Revista Brasileira de Filosofia, Rio de Janeiro, v. XLIII, n. 182, p. 182-190, abr./jun. 1996.

MAIA, A. C. Direitos humanos e a teoria do discurso do direito e da democracia. In: MELLO, C. D. de A.; TORRES, R. L. (Org.). Arquivos de direitos humanos. Rio de Janeiro: Renovar, 2000. (v. 2).

MERLE, J.-C.; MOREIRA, L. (Org.). Direito e legitimidade. Tradução de Claudio Molz e Tito L. C. Romão. São Paulo: Landy, 2003.

NAGEL, T. Personal Rights and Public Space. In: KOH, H.; SLYE, R. C. Deliberative Democracy and Human Rights. New Haven: Yale University Press, 1999, p. 33-90.

NAHRA, C. Tugendhat e os direitos humanos. In: DALL'AGNOL, D. (Org.). Verdade e respeito: a filosofia 
de Ernst Tugendhat. Florianópolis: Editora da UFSC, 2007.

NINO, C. S. Ética y derechos humanos: un ensayo de fundamentación. Buenos Aires: Astrea, 1989.

Derecho, moral y política: una revisión de la teoría general del derecho. Barcelona: Editorial Ariel, S. A. 1994.

PIOVESAN, F. Direitos humanos e o direito constitucional internacional. São Paulo: Max Limonad, 1997.

ROHDEN, V. (Coord.). Kant e a instituição da paz. Porto Alegre: Ed. Ufrgs/Goethe-Institut, 1997.

SILVA, A. G. da. Teoria do discurso, construtivismo filosófico e razão prática. Virtú, Revista Virtual de Filosofia Jurídica e Teoria Constitucional, n. 2, 2008. Disponível em: $<$ http://vlex.com/vid/discursoconstru-tivismo-filosofico58965996 $>$. Acesso em: 12 dez. 2010.

TORRES, R. L. (Org.). Legitimação dos direitos humanos. Rio de Janeiro: Renovar, 2002.

TUGENDHAT, E. Lições de ética. Tradução de Ernildo Stein et al. Petrópolis, RJ: Vozes, 2003.

WOOD, A. Kant. Tradução de Delamar José Volpato Dutra. Porto Alegre: Artmed, 2008.

\section{Notas}

1 Kelsen (1991, p. 75) afirma que "a ciência jurídica não tem que legitimar o Direito, não tem de forma alguma de justificar-quer através de uma Moral absoluta, quer através de uma Moral relativa-a ordem normativa que lhe compete - tão-somente - conhecer e descrever."

2 Expressão utilizada por Axel Honneth (2003).

3 Para uma distinção entre os termos "fundamentação", "legitimação", "justificação” ver Silva(2008).

4 Expressão utilizada por Dutra (apud FELDHAUS, 2007, p. 13).

5 Não é nosso objetivo, até porque foge ao escopo desta investigação, uma análise exegética da concepção kantiana de razão prática. Vamos apresentar apenas alguns elementos teóricos centrais que nos permitem reconhecer os fundamentos kantianos das teorias da razão prática relacionados aos fundamentos filosóficos dos direitos humanos.

6 Cabe esclarecer que Kant critica não só o rigorismo do positivismo jurídico, mas tambémuma privatização da moral.
Ele rejeita toda moralização do direito, como advindo de uma moralidade pessoal. Kant deriva o direito da razão prática pura e do seu critério da legalidade universal (HÖFFE, 2005, p. 232-233, 240-241).

7 “A estratégia de legitimação dos direitos humanos desenvolvida por Robert Alexy insere-se no pensamento moral kantiano e, nesse sentido, a sua compreensão teórica é informada por dois princípios fundamentais, quais sejam: a universalidade de tais direitos e a autonomia de seus titulares" (SILVA, 2008, p. 22).

8 Para estudos dessas diferentes posições, ver: Barbosa (2002), Dutra (1998), Fernandez(1991), Ferrajoli (2001), Merle(2003) e Torres (2002).

\section{Giovani Mendonça Lunardi}

giovaniunir@gmail.com

Doutorado em Filosofia pela Universidade Federal do Rio Grande do Sul (Ufrgs)

Professor Adjunto na Universidade Federal de Santa Catarina (UFSC/Campus Araranguá)

UFSC - Campus Araranguá

Rua Pedro João Pereira, n. 150

Bairro Mato Alto

Araranguá - Santa Catarina

CEP: 88900-000 